\title{
Management of functionaries' development of the enterprise management system by application of the criteria experts assessment by method of functional reliability
}

\section{Victor Petrenko* (D), Roman Psiuk**iD}

Ivano-Frankivsk National Technical University of Oil and Gas,

15 Karpatska str., 76019 Ivano-Frankivsk, Ukraine

* Doctor of Economic Sciences, Professor, Department of Public Management and Administration

** Postgraduate Student, Department of Public Management and Administration

\section{open (e) access (co)}

Article history:

Received: February 5,

2018

1st Revision: February 25,

2018

Accepted: March 21, 2018

JEL classification:

M12

015

DOI:

10.14254/jems.2018.3-1.5

\begin{abstract}
Emphasis on the importance and necessity of human resources management at the enterprise is made. It was emphasized that special attention should be paid to the evaluation of managers, in particular the characteristics of their functional suitability. The functional characteristics of the company's managers, necessary for the accomplishing of tasks, are highlighted. The expediency of research and of the managers' behavior evaluation results at the enterprise was substantiated in order to form such characteristics of its activity that would contribute to the achievement of the strategic goals of the enterprise through the proper management of human resources development. The original methodology for conducting of such evaluation is proposed and conclusions and recommendations are made regarding the formulation of strategic goals of human resource development management. The necessity of taking into account the conditions of the manager work environment, in particular, the number of people in the subordination, to choose the methods of their training and development, is substantiated.
\end{abstract}

Keywords: manager, behavior, strategy, human resources, development of enterprise, management, results.

\section{Introduction}

Successful operation and development of an enterprise depend on virtually unlimited number of factors. However, one of the most influential and decisive factors among these factors in the era of globalization and intellectualization of the economy are the human resources of

Corresponding author: Roman Psiuk

E-mail:psyuk@ukr.net

This open access article is distributed under a Creative Commons Attribution (CC-BY) 4.0 license. 
enterprises, the smallest of whom participate in the management of the enterprise (the management subsystem - managers and functionaries of the management system), and much more of them (a managed subsystem - executive staff) - transform their management decisions and guidance in the processes and procedures for the performance of official duties provided by the plans and production program. Thus, it is people who have a decisive role in achieving the company's established plans and programs of management goals. At the same time, the effective interaction of these subsystems is also determined by other factors of the enterprise's development, therefore, human resources management should be carried out by a management subsystem with maximum consideration of the most influential factors and goals of the general development strategy, since this strategic resource is being implemented by this resource component. Therefore, the strategic objectives and principles of human resources management of the enterprise should cover and take into account the whole set of influential factors that requires from the management of the management subsystem of the use of relevant behavior and management styles capable of ensuring the best interaction of the components of a typical management pair, the executing-executive in an intellectualized economy that will lead enterprise to market success.

Due to the fact that today any enterprise needs the selection of such managers who possess the necessary for intellectualized management of features and characteristics, it is expedient to further explore the approaches, methods and tools for assessing the behavior of managers in the processes of providing functional units of enterprises to achieve their strategic goals.

The purpose of the paper is to create and test the method and tool for analysis, evaluation, and, if necessary, correction of the behavior of managers of the functional units of enterprises by identifying their personal characteristics and preferences in the processes of establishing and realizing the goals of their personal development in accordance with the goals and objectives of enterprise development.

\section{Materials and Methods}

Human resources management (HRM) is an activity directed to the proper formation and efficient use of this type of resource support for any enterprise, institution or organization. The modern paradigm of HRM at the enterprise has replaced from the traditional processes of administration and personnel management - the concepts that are much narrower, oriented to the regulated hiring procedures, regulation of labor relations, systems of wages, pension payments, etc. The modern approaches to the HRM are designed to integrate people into the processes of strategic planning of the enterprises and organizations more fully, and, unlike the personnel management process, consider people's work not only because of their contribution to the achievement of the goals of enterprise development, but also because of the ability to increase this contribution by development and effective manifestations of their intellectual potential. As a result the enterprise form a complex of non-material motives, motivators and stimuluses directed to the increasing of the efficiency not only of their physical but also the intellectual work is a contribution to the overall results (Petrenko, Kis, \& Shvedkyi, 2013; Sitnik, 2017; Kotovska et al, 2016).

Obviously, any enterprise or organization has specific requirements for labour force (both executives and executors) whose compliance can guarantee their success. The establishment of these requirements is mandatory for both the management corpus and all staff. However, the requirements for enterprise executives and functioners of the management system who are the leaders of the divisions, whose role in achieving the goals of the divisions in particular and the enterprise as a whole is a priority, are specific. Indeed, it depends on them the level of staff integration in the decision-making processes on improving the basic, supporting and auxiliary processes in all spheres of enterprise activity. In addition, managers of different departments, interacting with each other, must possess the basic functional competencies that are specific to the fields of activity and responsibility of the units headed by them.

Specialists in the field of leadership, exploring the behavior of managers, distinguish characteristics necessary for successful leadership. In particular, the model P. Coestenbaum highlights the following functions of personality: care for people, observance of moral principles (ethics); application of analytical thinking skills; choice of new ways of motivation to work (vision); manifestation of initiative, responsibility, freedom of decision (courage); purposefulness and orientation on the results of activity (realism) (Koestenbaum, P., 1991). Compliance with them is necessary for the effective management of the characteristics, which is the key to the proper performance of the tasks assigned to the executives.

As a result, the activity of each enterprise's division should be provided by the general management function on the basis of the maximum effective implementation of special 
management functions related to the level of efficiency of the work of a separate division or sphere of activity. Then, in general, the activity of human resources of the enterprise should be in line with a coherent mechanism that would continue to perform its functions, even under conditions of not very high-quality execution or certain violations of at least one of the traditionally required management functions (Figure 1).

The functioning of such mechanisms is associated with a number of criteria, in particular: the formation of an enterprise development strategy and the selection of personnel that will be able to fulfill the tasks; creation of an adequate organizational structure that would ensure proper interaction and transfer of authority; the formation of a corporate culture and the main provisions of the philosophy of the enterprise, which would contribute to the achievement of the goals (Koestenbaum et al, 2006).

It is obvious that only those managers who possess the relevant qualifications and have the necessary competencies that determine his working behavior can meet these requirements.

\section{Figure 1: Interaction of enterprise divisions in achieving strategic goals of enterprise development}

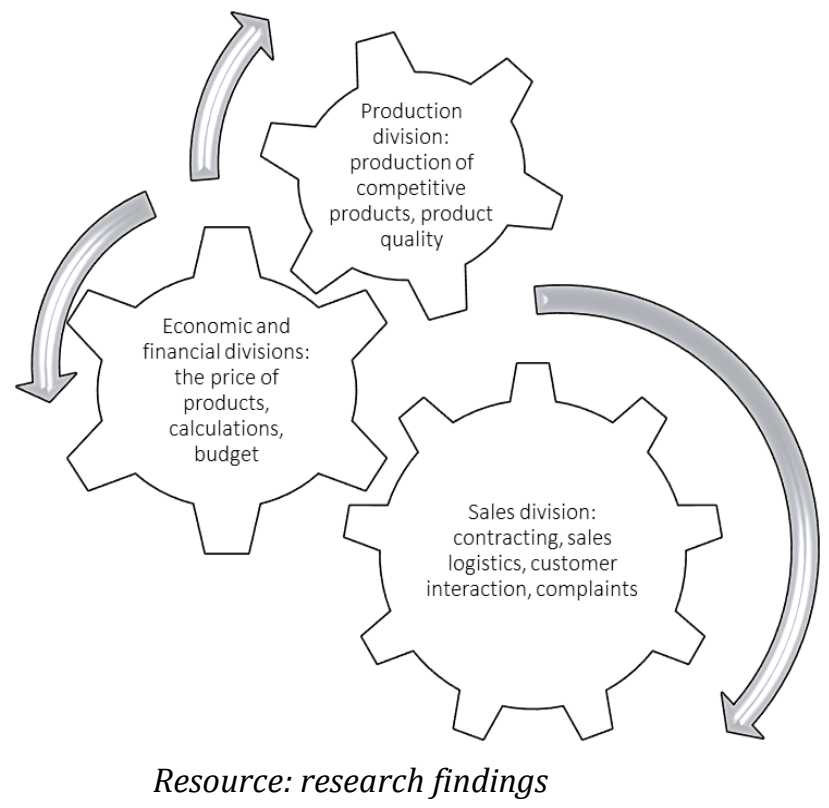

A complex is needed to ensure the proper behavior of the manager's characteristics, which is determined by his knowledge, experience, skills and roles in the performance of the tasks and testifies to his desire for continuous improvement (Rayevneva, 2006, Yerokhina, Kopaigorodskaya, \& Ladunka, 2011). We propose to evaluate the level of potential of manager's characteristics development and an assessment of this level to perform by a method of evaluating these characteristics using specially designed questionnaires.

The point assessment of the manager's characteristics we are invited to perform on the following five criteria-characteristics of their functional suitability, which allow to assess:

- $\quad$ the ability of the manager to perform the required division of the task and role $(r)$;

- the manager's communication skills and his ability to communicate with representatives of other enterprises and, in particular, enterprises from other countries $(e)$;

- $\quad$ the manager's ability to initiate changes, to be an innovator and integrator, uniting the efforts of the unit's employees to perform the assigned tasks, and to reasonably make risky decisions (i);

- $\quad$ analytical skills that allow the manager to evaluate the situation and forecast possible scenarios of its development $(a)$;

- level of awareness by the manager of the necessity and expediency of further education and development $(p)$.

At the same time, one should proceed from the fact that the manager, being unable to become the "ideal leader" (Deryabin, 2008) and equally perfectly possess all these characteristics, must have at least one, and even better, two of the listed characteristics and, if necessary, develop and reinforce others (I. Adizes). 
Considering that, as a rule, the strategy of human resources development at the enterprise should correspond to the strategy of the enterprise and the philosophy of corporate culture; for the development of the ability to manage the employees of individual units it is expedient to choose the characteristics that allow the most effective management of the implementation of the specific functions of the unit located in the zone competence and responsibility of its head.

For example, the department of foreign economic relations needs workers who, besides the competences related to functional work, must also possess new knowledge about the specifics of cooperation with foreign partners, and their manager, besides management, should also have a significant list of competencies and features that allow them not only to perform specific functions on its own, but also managerial functions related to the work of the headed division in new sale markets, with new partners, in the new multi-cultural environment.

A well-known method of interviewing experts can be chosen as a method of research and evaluation of the dominant characteristics of the behavior of managers, and the results of which will be sufficient to carry out the ranking of the responses obtained in the course of the survey on the degree of their weight in accordance with (Grabovetsky, 2010).

The task of evaluating of the dominant characteristics of the functional division manager is to put the numbers from 1 to $\mathrm{m}$ in the system with the $\mathrm{m}$ obtained in the process of interviewing expert evaluations.

Therefore, marking through $R_{i j}$ the estimate assigned to the $j$-th criterion of the $i$-th respondent, we will put all the obtained results of the survey in Table 1 so that to find a summary of each of the above criteria for evaluating the characteristics of the managers $R j$ based on the data concentrated in it by the formula 1 :

$$
R_{j}=\sum_{i=1}^{n} R_{i j},(\mathrm{j}=\overline{1, m})
$$

The calculations performed in this way allow us to generalize the priority of these criteria as presented in formula 2, starting with the least influential to the most influential on the behavior of the head of the characteristic:

$$
a>p>e>i>r
$$

The degree of concordance of the conclusions drawn by experts is the coefficient of concordance $W$, which, in the case of strict ranking (evaluation is made within the established criteria), are calculated by the formula:

$$
W=\frac{12 \sum_{j=1}^{m}\left(R_{j}-(\bar{R})^{2}\right.}{n^{2}\left(m^{3}-m\right)}, W \in[0 ; 1],
$$

\section{Research results}

The calculations performed with using of expressions (1), (2) and (3), and the results of the evaluation by the experts of the characteristics of the 8 respondents - the managers of the functional units of the enterprise: production, commercial, financial, planning and economic, which closely interact with the sales function on the enterprise, according to the criteria $a, p, e, i, r$, is presented in Table 1.

The use of the correlation analysis method has allowed to obtain an assessment of the influence of managers' characteristics, in particular the "number of people in subordination" and "age" on the obtained score $(r)$ - the ability of the manager to perform the required by division tasks and roles. Table 2 shows the values of correlation coefficients calculated at the EXCEL analysis package with using of indicated indicators.

Thus, from the data in Table 2, we can conclude that "age" does not have a significant effect on the functional characteristics of managers. However, the "number of people in subordination" has a significant impact on the obtained score $(r)$ and $(p)$. Consequently, we can assume that a significant number of subordinators in the subordination requires a significant attention of the manager to the organization and the implementation of the responsibilities assigned to the managers' functions. But this may interfere with the development of others functions necessary for the managers as well as the successful functioning of the division headed by him. And this, in turn, will require the search for methods of training and development of human resources at the enterprise. 


\begin{tabular}{|c|c|c|c|c|c|c|c|c|}
\hline \multirow{2}{*}{$\begin{array}{c}\text { Respondents } \\
\text { (i) }\end{array}$} & \multicolumn{5}{|c|}{ Obtained scores $(j)$} & \multirow{2}{*}{ Age } & \multirow{2}{*}{ Department } & \multirow{2}{*}{$\begin{array}{c}\text { Number of } \\
\text { people in } \\
\text { subordination }\end{array}$} \\
\hline & $r$ & $a$ & $i$ & $e$ & $p$ & & & \\
\hline 1 & 4.1 & 3.2 & 3.30 & 4.30 & 4.20 & 47 & Production division & 30.00 \\
\hline 2 & 4.1 & 4 & 3.60 & 3.30 & 4.5 & 46 & $\begin{array}{l}\text { Commercial } \\
\text { division }\end{array}$ & 20.00 \\
\hline 3 & 4.8 & 4.2 & 5.00 & 4.00 & 4.9 & 47 & $\begin{array}{l}\text { Commercial } \\
\text { division }\end{array}$ & 40.00 \\
\hline 4 & 4.2 & 3.9 & 3.70 & 4.30 & 3.6 & 38 & $\begin{array}{l}\text { Commercial } \\
\text { division }\end{array}$ & 14.00 \\
\hline 5 & 4.5 & 4.3 & 4.50 & 4.10 & 3.6 & 31 & Economic division & 23.00 \\
\hline 6 & 4 & 4.6 & 4.80 & 4.30 & 2.9 & 47 & Economic division & 10.00 \\
\hline 7 & 4 & 3.5 & 4.40 & 4.40 & 4.5 & 39 & Financial & 7.00 \\
\hline 8 & 3.6 & 3 & 3.50 & 3.3 & 3.4 & 22 & IT division & 3.00 \\
\hline$\sum R i j$ & 33.3 & 30.7 & 32.8 & 32 & 31.6 & & & \\
\hline
\end{tabular}

Resource: (Petrenko et al, 2013; Sitnik, 2017; Koestenbaum, 1991; Shelegeda et al, 2006; Rayevneva et al; 2006)

Table 2: Value of the correlation coefficient

\begin{tabular}{lccccc}
\multicolumn{1}{c}{ Indicator } & \multicolumn{4}{c}{ Value of the correlation coefficient } \\
\cline { 2 - 6 } & $r$ & $a$ & $i$ & 0 & 0,369083 \\
\hline Age & 0,420027 & 0,431979 & 0,24608 & 0,402008 \\
Number of people in subordination & 0,840621 & 0,265446 & 0,227958 & 0,132669 \\
\hline
\end{tabular}

To sum up the results of obtained in Table 1 values of the results of the departmental executives survey connected with the sales function, we will determine the coefficient of concordation - the coherence of the evaluation results of the considered example, which requires the performance of intermediate calculations, in particular:

$$
\begin{gathered}
\bar{R}=\frac{n(m+1)}{2}=24, \\
\sum_{j=1}^{5} R_{j}=160.4, \\
W=\frac{12 \times 330.58}{64(125-5)}=\frac{3966.96}{7680}=0.517
\end{gathered}
$$

As a result, we note that the highest level of concordance of the obtained estimates corresponds to the value of the coefficient that is approaching to 1 .

Using the data in Table 1, we find a summary of each of the criteria for characteristics evaluating of the manager $R_{j}$ due the expression (1).

For the verification of the significance of the coefficient of concordance we use the criterion $\mathrm{x}^{2}$ of $(\mathrm{m}-1)$ degrees of freedom. In this case, the estimated value of the criterion statistics $\mathrm{x}^{2}=\mathrm{Wn}(\mathrm{m}-1)$ is compared with the table values for the selected probability level. If the estimated value exceeds the tabular one, then the concordance of respondents' answers is confirmed.

For the considered example, the estimated value of criterion statistics is:

$$
\mathrm{x}_{\text {calcul }}{ }^{2}=0,517 \times 8 \times 4=16.5
$$

From the distribution tables $\mathrm{x}^{2}$ for the level of significance 0.05 and the degree of freedom 4 we find $\mathrm{x}_{\text {crit }}{ }^{2}=9.5$. Since the estimated value of statistics is greater than the table, the obtained results of the ranking can be considered statistically significant.

Thus, the researches made allow us to conclude that the activity of the division managers at the investigated enterprise is estimated by the high (the highest compared with other characteristics) ability of the manager to perform the tasks and roles, which testifies to the proper setting of the level of executive discipline. However, the high significance of one of these 
characteristics is not enough to provide the quality performance of other responsibilities assigned to the head of functions. Thus, in conditions of implementation of the development strategy it is necessary to develop the characteristics of initiative and innovation; in the conditions of sharpen of competitive relations, the weight of analytical skills increases; the expansion of the partnership leads to the improvement of manager's communicative skills.

The obtained results of the conducted survey can summarize that the significant influence on the forming of dominant functional characteristic of managers $(r)$ for the selected enterprise has the "number of people in subordination".

\section{Conclusions}

Thus, management of enterprises should pay considerable attention to the regular study and evaluation of the behavior characteristic of the managers of functional units in order to control their ability to perform their functions.

Due to this purpose, we have proposed an advanced methodology for expert evaluation of the characteristic criteria of managers' potential with using of mathematical tools to confirm the reliability of the results. For the purpose of obtaining objective results, the method of alternative assessments ranking by their degree of weighting has been applied. The coefficient of concordance of the received evaluation results of the managers' behavior has been calculated and the statistical significance of the obtained results has been determined.

Using the calculation of the correlation coefficient, the influence of the manager's characteristics on the evaluation obtained as a result of the survey is determined. It is substantiated that for the managers' harmonious development it is necessary to create conditions for its comprehensive development at the enterprise.

It has been shown that it is expedient for the managers of functional units to control and develop their characteristics in the first place according to those criteria, the assessments of which are not high enough. This will help to improve the performance of the tasks assigned to their departments by the strategy of personnel development of the enterprise.

\section{Appendix A. Supplementary material}

Supplementary data associated with this article can be found, in the online version, at https://dx.doi.org/10.14254/jems.2018.3-1.5

\section{Funding}

The authors received no direct funding for this research.

\section{Citation information}

Petrenko, V., \& Psiuk, R. (2018). Management of functionaries' development of the enterprise management system by application of the criteria experts assessment by method of functional reliability. Economics, Management and Sustainability, 3(1), 58-64. doi:10.14254/jems.2018.3-1.5

\section{References}

Adizes, I. (2017). Ideal leader. Why it is impossible to become. Kyiv. [in Ukrainian].

Deryabin, G.V. (2008). Psychological Peculiarities of Development of Management Potential of Personality. (Candidate of economy science dissertation abstract of thesis 08.06.01). Kyiv. [in Ukrainian].

Feschur, R., Kichor, V., Yakimov, A., Timchishin, I., Yanishevsky, V., et al. (2013). Adoption of design decisions. (Textbook). Lviv, Lviv Polytechnic Publishing House. [in Ukrainian].

Grabovetsky, B. Ye. (2010). Methods of expert assessments: theory, methodology, directions of use: monograph. Vinnitsa, Publishing House of Vinnitsa National Technical University. [in Ukrainian].

Koestenbaum, P. (1991). Leadership: The Inner Side of Greatness, A Philosophy for Leaders, New and Revised Hardcover. Jossey-Bass Inc., Publishers. [in English].

Kotovska, I., Oksentyuk, R., \& Vovk, Yu. (2016). Kouchynh yak novyi metod upravlinnia personalom [Coaching as a new method of human resources management]. Socio-Economic Problems and the State, 14(1), 178-184. [in Ukrainian]. 
Ladunka, I. S. (2011). Implementation of an integrated assessment of the competitive advantages of management personnel. State and Regions. Series: Economics and Entrepreneurship: Research and Production Journal. Zaporizhya, 3, 140-143. [in Ukrainian].

Methodology of the Adizes. (2017). Retrieved from https://adizes.me [in Russian].

Petrenko, V.P., Kis, S. Ya., \& Shvedkyi, E. A. (2013). Management of enterprises activity of the oil and gas complex on the basis of intellectualization and intellectual use. (Monograph). Lviv, Publishing House Pyramid. [in Ukrainian].

Rayevneva, O. V. (2006). Management of enterprise development: methodology, mechanisms, models. (Monograph). Kharkiv, Publishing House INZHEK. [in Ukrainian].

Shelegeda, B., Kasyanova, A., Bersutsky et al. (2006). Strategic management of enterprise potential. (Monograph). Donetsk, Publishing House of Donetsk University of Economic and Law. [in Ukrainian].

Sitnik, J. (2017). Intellectualization of enterprise management systems: concept, system monitoring and modeling. (Monograph). Lviv, Lviv Polytechnic Publishing House. [in Ukrainian].

Yerokhin, T., \& Kopaigorodskaya, T. Management potential: the essence and role in enterprise management. Retrieved from http://nauka.kushnir.mk.ua/?p=8811. [in Ukrainian].

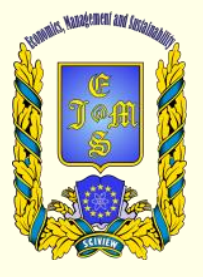

(c) 2016-2018, Economics, Management and Sustainability. All rights reserved.

This open access article is distributed under a Creative Commons Attribution (CC-BY) 4.0 license.

You are free to:

Share - copy and redistribute the material in any medium or format Adapt - remix, transform, and build upon the material for any purpose, even commercially.

The licensor cannot revoke these freedoms as long as you follow the license terms.

Under the following terms:

Attribution - You must give appropriate credit, provide a link to the license, and indicate if changes were made.

You may do so in any reasonable manner, but not in any way that suggests the licensor endorses you or your use.

No additional restrictions

You may not apply legal terms or technological measures that legally restrict others from doing anything the license permits.

Economics, Management and Sustainability (ISSN: 2520-6303) is published by Scientific Publishing House "CSR", Poland, EU and Scientific Publishing House "SciView", Poland

Publishing with JEMS ensures:

- Immediate, universal access to your article on publication

- High visibility and discoverability via the JEMS website

- Rapid publication

- Guaranteed legacy preservation of your article

- Discounts and waivers for authors in developing regions

Submit your manuscript to a JEMS at http://jems.sciview.net or submit.jems@sciview.net 